\title{
Thinking of Teaching Reform about "Metal Material Science" Based on Ability Cultivation Training
}

\author{
Nengwei WANG ${ }^{\mathrm{a}}$, Yucheng $\mathrm{YU}^{\mathrm{b}}$, Zhenling WANG ${ }^{\mathrm{c}}$ \\ College of Vanadium and Titanium \\ Panzhihua University \\ 617000 Panzhihua, Sichuan Province, China \\ a 476693298@qq.com, b30035957@qq.com, ${ }^{\mathrm{c}}$ 28930016@qq.com
}

\begin{abstract}
In order to solve the problem of the trouble in the study about "Metal Material Science" for the students and that of some difficulties in the course teaching for the teachers, the paper puts forward a variety of teaching methods based on the ability cultivation training innovatively by analyzing objective reasons for existence. Many reform ways are introduced including the interactive teaching mothods and mixed teaching methods and the enthusiasm of the students for learning is mobilized. On the other hand, the teaching reform is fully combined with the practice teaching. The results show that the implementation of a variety of measures must lead to a new step in the teaching of the "Metal Material Science".
\end{abstract}

Keywords-Metal Material Science; course teaching; cultivation training; reform.

\section{INTRODUCTION}

Last year several students in our college successfully passed the first entrance examination of graduate students in order to study in a famous university. At the stage of reexamination, the written examination for specialized courses and English examination were still smooth. But when they got into a professional interview, there were many questions about some practical applications involved in Metal Materials Science, for examples, some questions such as "what is the possible cause of cracking of alloy steel during quenching?" and "Why does High Speed Steel need Red hardness as cutting tool?" and so on. The students thought they would be able to cope with the questions easily because they were familiar with some theoretical knowledge in the textbooks. But they couldn't answer such questions very well. At last they had to accept the bitter consequences of the failure of the interview and had to enter other colleges and universities. As a teacher, it was also quite helpless to hear the news reflected by the students. In fact, it also reflected that there must be some problems in the teaching of "Metal Materials Science ". Therefore, it was necessary to strengthen the in-depth reform of this course; we must pay attention to enhancing the cultivation of students' ability.

Metal Material Science is a very important major course for students in metal material engineering. The main contents of the course are as follows: alloying elements in steel, engineering structure steel, tool steel, dies steel, high speed steel, stainless steel, nonferrous alloy, etc. The core of the study is the composition, microstructure, properties and processes of Metal materials[1-4]. So the main line of learning this course should be how to improve the performance of metal materials. The way is to select the appropriate metal composition, control the ideal microstructure and determine the reasonable heat treatment process. The course is characterized by many concepts of technical terms, wide and scattered knowledge points, abstract and difficult to understand, more obscure and boring content. In the new situation, the requirements can't be met for the traditional teaching model and teaching content no longer. In order to fully mobilize the students' enthusiasm and initiative in learning, it is particularly important to strengthen the cultivation of students' creative thinking and practical ability, and to reform and optimize the course teaching[5-6].

\section{THE OVERALL GOAL OF CURRICULUM REFORM}

The overall goal of the course reform of Metal Material Science is to take the training model of excellent engineers as the guidance. The starting point is to realize the full employment of students and the diversion of further study. In order to raise students' engineering consciousness and innovation consciousness, high-quality practical engineering technical talents with "thick foundation and wide caliber" for the society can be really cultivate. On the premise of a limited number of hours, the content of the syllabus should be adjusted reasonably; the basic theories and applications in the course of Metal Material Science should be integrated organically. Based on the basic theories of the traditional classics, the knowledge of metal materials should be expanded, new theories, new techniques and methods, and new ideas should be actively introduced into the teaching of theory. To make full use of all kinds of teaching resources, teaching means should be reformed and a harmonious teaching method system should be formed, then the students' ability to analyze and solve problems can be effectively improved.

\section{SEVERAL ASPECTS OF TEACHING REFORM}

\section{A. Reform of teaching content}

The course of "Metal Materials Science" is based on the four main elements, including contents, microstructure, 
technology and properties of material science research. These four elements should be grasped tightly in the course of teaching. For students, they are often not content with traditional knowledge systems, they are more curious about new theories, new ideas, new methods. Especially they are interested in cutting-edge knowledge of the subject. So their mindset should be grasped and some new ideas should be added to the explanation of the basic theory. For example, with regard to the chapter on proliferation, the Kekendall effect is a powerful evidence of mutual diffusion between the two metals. It is caused by the different diffusion rates of each component in the multi-element system, which results in the phenomenon that the original boundary of the diffusion couple moves towards one side of the fast diffusion rate. The theory was confirmed by experiments by Kekendall and Smigeiska in 1947[7]. Because of its classic nature, it is easy for students to grasp. In fact, it is easy to verify with the combination of scanning electron microscopy (SEM) and energy dispersive spectroscopy (EDS) in modern test methods. Firstly, the binding site of the two metals can be found by using the scanning electron microscope image acquisition function, secondly, the face scan or line scan in the "Smartmap" function in EDS can be used; it takes less than a few minutes to come to the conclusion of diffusion. This method is both advanced, fast and intuitive, and modern advanced test methods are used to explain classic experimental phenomena. For another example, according to the traditional heat treatment theory, the quenching of sub-eutectic steel must be heated to $30^{\circ} \mathrm{C}$ above Ac3 temperature and $50^{\circ} \mathrm{C}$ for complete austenitization, in order to avoid the occurrence of ferrite in steel. After quenching, normal martensite structure or lower bainite structure can be obtained. It has been proved that subtemperature quenching is a new type of heat treatment process, which is strengthened and toughened by super-fine composite structure. It deviates from the traditional theory of quenching process. The steel is heated to a certain temperature range (Ac1 Ac3) in the $\alpha+\gamma$ dual phase region and quenched after holding for a certain period of time. Although the strength decreases slightly, the low temperature plasticity and toughness are improved, and the comprehensive mechanical properties of metals are also improved. This process has attracted enough attention and has been widely used.

\section{B. Reform of teaching methods}

In facts, it has proved that the ideas of teachers and books were infused into students by the education way of "duck-feeding", teachers became "solo dancers", and the teaching process was not creative. Today, when quality-oriented education is vigorously advocated, the drawbacks of "duck-feeding" education have been widely criticized, especially for higher education. It is a professional basic course for "Metal Materials Science". It is very closely related to practical application, so it is more necessary to adopt heuristic education in teaching methods. For example, the material used for Vernier calipers is GCr15 steel. The processing process is as follows: quenched and tempered (quenched and high temperature tempering), rough processing, quenching, low temperature tempering, stabilization processing and stabilization treatment. So is the process reasonable? It is normal for students to encounter such problems. A heuristic education method can be adopted to tell students that the
Vernier caliper needs good dimensional stability besides wear resistance and corrosion resistance as well as a precision measurement tool. Therefore, students can be asked in time what problems they should pay attention to their organizational control and whether the operating conditions of the Vernier calipers can be met for the existing organizations. Students can be guided to have appropriate classroom discussions, the results of the discussions can be summarized and the wrong answers can be eliminated. In this process, the role of the teacher should be to match the bridge; the initiative is left to the students. Such a teaching process is believed to be universally welcomed by students, thus the quality of classroom teaching can be improved effectively.

At present, teaching methods are becoming more and more diversified, such as classes, flipping classes, divided classes, mixed teaching methods and so on. The purpose is to fully mobilize the enthusiasm of students and give the initiative of learning to the students. In the case of mixed teaching, it is indeed useful to use this teaching method in Metal Material Science. Teachers upload a large number of materials to the network class, and assign some exercises; students complete the relevant content by self-study. In the classroom, the teacher interacts with the students according to the problems left in the network class, and tests the students' undefined learning effect, and explains the difficult points, which is much better than cramming education in the past.

\section{Teaching reform of sustainable learning}

It is not realistic and impossible to absorb all the theoretical basic knowledge in classroom time, so it is necessary to advocate sustainable learning method. In fact, there are many means of sustainable learning, including arranging exercises and discussion questions after class, leaving self-study content after class, urging students to look up relevant materials on the internet or in the library, and so on. The best way to achieve sustainable learning is to arrange a scheduled after-class answer. There are a lot of content, large capacity and wide knowledge for college teaching in each class. Students should digest many difficulties in classroom teaching after class, but it is difficult for students to digest and absorb them in such short time. If the difficulties of knowledge that students should master in each class are not solved in time, it is bound to affect the students' follow-up study. Therefore, it is very necessary to arrange to answer questions[8-9]. By answering questions, "win-win" can be obtained for teachers and students: after answering questions, students can effectively eliminate the blind spots of knowledge, and teachers also understand the extent of students' mastery of knowledge and the crux of the questions. It provides a basis for teaching improvement in the future. Therefore, answering questions is the most direct, ideal and most popular way for students to learn sustainably. In the process of answering questions, the relationship between students and teachers is no longer like the strict teacher-student relationship in the classroom. It is a kind of friend relationship which takes the knowledge exchange as the carrier, the student admires the teacher' profound knowledge, the teacher is also willing to impart to the student the answer, the student's study ability unknowingly improves.

The combination of in-class and extracurricular learning is also an effective way to achieve sustainable learning. Many 
teachers attach importance to in-class learning, but the management of extracurricular learning is not well implemented, so that this effective way is lost. For the extracurricular study of Metal Material Science, the students should not simply be urged to consult the extracurricular materials, but should be put forward the specific goals to be achieved in view of some difficult and doubtful knowledge in the classroom or combined with the practical production and application. With targeted guidance, students are required to complete intended target within the prescribed time. For example, as for the chapter of recovery recrystallization, how to use this theory to obtain ultra-fine grain steel. After the question is put forward, students should be instructed about how to control the deformation mode, deformation rate, recrystallization temperature and time, and then the students also should be instructed to look up the related books. When students have a definite task, they will look up the data through many ways after class, then collect and analyze the data, and get a perfect craft route, so the goal of sustainable learning can be achieved.

\section{Practice teaching reform}

Practical teaching strengthened is beneficial to promote theoretical teaching, and the effect of theoretical teaching needs to be tested in practical teaching, which has become the consensus for all people[10-13]. The content of the course is rich in theory. It also has distinct practicality. Therefore, it is necessary to carry on the effective reform to the practice teaching. The traditional experimental course does play a certain role in cultivating students' basic experimental practical ability and experimental skills, but the students are carried out in the steps of teachers or experimental teaching materials, and students' practical learning has always been in a passive state. It is difficult to give play to their innovative thinking, and is less motivated. Therefore, in the process of experiment teaching, the single operational and confirmatory experiment is transitioned to design and synthesis, and the students are encouraged to complete the experiment independently, so as to improve the students' ability of analyzing and solving practical problems. For example, it is possible to combine hardness testing with heat treatment of steel to develop a design and comprehensive experiment, "how to control the hardness of annealed 45 steel between HRC 25 and HRC 30." Experimental teachers can inspire students to consult the relevant materials, and guide students independently to analyze and design the experimental scheme. There may be many kinds of experimental schemes, and the experimental teacher can guide the students to put forward the best experimental scheme, and then the students can carry on the experimental operation. In the whole process, the teacher gives the initiative of practical learning to the students, so as to achieve the purpose of comprehensive and comprehensive professional skills training.

\section{CONCLUSION}

The teaching reform of Metal Material Science based on ability training is a reform activity involving a wide range of areas, strong scientific nature and arduous tasks. The reform of curriculum teaching must break through the traditional curriculum teaching mode. The aim of this paper is to improve the students' ability of practical application and innovation, to train outstanding engineers in material science as the guidance, and to cultivate high-quality professional and technical personnel of application type for the society as the ultimate goal. The reform puts forward higher requirements for teachers Teachers not only need solid knowledge of basic theory, but also master some new theories, new technologies and new methods, and have sufficient practical experience in production, and in the course of teaching, they also need to master some new theories, new technologies and new methods. It combines the teaching contents with the design of teaching cases organically, and applies skillfully, fully arouses the enthusiasm and initiative of the students, so as to make the course teaching raise a new stage.

\section{ACKNOWLEDGEMENTS}

This work was financially supported by the mixed teaching reform of the school level (HJK1706-2018).

\section{REFERENCE}

[1] Li Hui, Jiao Lei, Lu Sheng, etc. Construction and Practice Reform of Innovative Courses in Metal Material Science[J]. Industry and Technology Forum, Vol. 13, pp. 140-141, 2014.

[2] Qu Li-jie, Ma Chun-li, Huang Zhi-xu, etc. Research on Teaching Reform of Metal Material Science [J]. Economic Enginee, Vol. 1, pp. 211-212, 2018.

[3] Meng Wei, Si Song-hua, Wang Yong-qiang, etc. Innovation and Practice of Teaching Reform in the Course of "Metal Materials Science"[J]. Higher Education, Vol. 1, pp. 135-136, 2018.

[4] Jiang Hong-jie, Yu Liang, Dong Yi-sheng, etc. Teaching Reform and Construction of Metal Materials[J]. Guangdong chemical industry, Vol. 43, pp. 134-137, 2016.

[5] Wang Song-lin. Exploration on Teaching Reform of "Application"-oriented Course" Metal Materials Science"[J]. Journal of Chi feng University(Natural Science Edition), Vol. 31, pp. 224-226, 2015.

[6] Ye Yong-quan, Liu Zhi-jun, Ye Mei-chao, etc. Exploration on Mixed Teaching Mode of Engineering Materials and Metal Technology[J]. Chinese Educational Technology Equipment, Vol. 12, pp. 91-93, 2018.

[7] Ma Jing-ling, Wen Jiu-ba, Ren Feng-zhang, etc. Reflections on the Teaching of Metal Materials Science in Engineering Education Certification[J]. EDUCATION TEACHING FORUM, Vol. 1, pp. 230-231, 2016.

[8] Li Qiang, Pan Deng. Exploration on Innovative Curriculum Construction and Practice Reform of Metal Materials Science [J]. Western Quality Education, Vol. 2, pp. 55, 2016

[9] Dai Qi-xun, Shao Hong-hong, Li Zhong-hua. Conception and Teaching Practice of the Excellent Course of Metal Materials Science[J]. Modern Education Scencie, Vol. 1, pp. 51-53, 2006.

[10] Zhao Li-ping, Sun Hao, Zhao Yong-tao, etc. Teaching Research on the Course of Metal Materials Science [J]. ZHONG GUO YE JIN JIAO YU, Vol. 1, pp. 10-12, 2013.

[11] Wang Ming-jing. Exploration and Research on Comprehensive Experimental Teaching of Metal Materials Science [J]. Higher education forum, Vol. 1, pp. 34-36, 2014.

[12] Guan Chunlong, Bi Xiaoqin, Bi Yu. On the Teaching Reform of the Course of Metal Materials Science[J]. Journal of Henan University of Technology (Social Science), Vol. 4, pp. 137-138, 2008.

[13] Zhang Yan. Researching of Blended Instructional Design Based on Deep Learning[J]. Microcomputer Applications, Vol. 34, pp. 32-34, 2018. 